\title{
Knowledge transfer and management among Malay traditional massage practitioners in the north of Malaysia
}

\author{
Norizan Esa ${ }^{1,1}$, Salasiah Che Lah ${ }^{2}$, and Sakiinah Mahamad Hakimi ${ }^{3}$ \\ ${ }^{1}$ School of Educational Studies, Universiti Sains Malaysia, 11800 Pulau Pinang, Malaysia \\ ${ }^{2}$ School of Humanities, Universiti Sains Malaysia, 11800, Pulau Pinang, Malaysia \\ ${ }^{3}$ Freelance researcher, Pulau Pinang, Malaysia
}

\begin{abstract}
Local knowledge is knowledge transferred across generations by individuals or community through experience in the environment they live in. This includes the knowledge and practices that are still practiced by a community or individual. Apart from trust, the willingness and capacity to share what they know and use what they learn plays an important role for local knowledge to be transferred and managed. In Malaysia, traditional Malay massage is a form of traditional healing among the Malay society that was recorded since the $19^{\text {th }}$ century through Kitab Tib manuscript. This form of healing uses natural resources, wafak (letters, numerals and diagrams), Quranic verses and doa (prayers and supplications) in the healing practice. This paper attempts to explore on how the knowledge is passed down from expert to apprentice. This study involves interviews and observation on selected Malay traditional massage practitioners. In conclusion, knowledge transfer among Malay traditional massage practitioners only happens when there is trust trust. Knowledge is passed down within their family members and learned from observation and experience. The traditional Malay massage remains only within the individual or a limited number within the family community rather than the community as a whole.
\end{abstract}

\section{Introduction}

Local knowledge is a knowledge passed on through experience from one generation to the next generation by individual or a community within the environment they live in. Local knowledge includes the knowledge, practices that are still practiced by a community or individual including language, place, spirits and world view [1]. Generally, the knowledge is transferred and managed when an individual or community trust each other and gain benefit from the transfer process.

Previous study found that, 'tacit knowledge' is not easy to be translated into written form such as documents, blueprints, and procedures. This knowledge can only be acquired from personal experience and difficult to be transferred and formalized. The transfer of knowledge usually learnt through apprenticeship via shared and collaborative experiences from expert to novice. The learning process requires 'doing' and participation from an expert to apprentice requires 'trust' for one to obtain the knowledge and skill desired. The higher the trust between the expert and novice, the more successful for the knowledge to be transferred [2]. For example, the transmission of environmental knowledge and land skills of 47 traditional Inuit men in Ulukhaktok, Canada. A list of 83 skills on the importance of safe and successful harvesting was passed down and transferred from older to younger generations through observation and apprenticeship in the environment. The loss of certain skills on hunting, fishing, trapping and incomplete transmission of knowledge was due to lack of skilled teachers, loss of native language, and changes in the educational environment [3].

The transmission of knowledge can also take place when there is a shared goal for technology and knowledge to be exchanged. The persistency of a novice in learning the knowledge is also an important factor for a knowledge to

\footnotetext{
${ }^{1}$ Corresponding author: salasiah@usm.my
} 
be successfully transferred. Other than that, technical capability, strategic and cultural compatibility also becomes one of the success factors for the knowledge to be transferred. The more persistent the novice show in learning the knowledge, the higher the trust between the expert and novice. Through persistence and trust, the knowledge can be exchanged easier [2].

An example of tacit knowledge in Malaysia is the knowledge on traditional massage, whereby it falls under Traditional and Complementary Medicine. Traditional massage is practiced together other than the practice of medicine or surgery by registered medical practitioners defined in the Medical Act 1971 approved by Malaysian Medical Council, Ministry of Health Malaysia [4]. In the context of local knowledge, the knowledge is learned from personal experience, shared and collaborative experiences which require participation and 'doing'. However, since local knowledge can only be obtained through trust and shared goals, the transfer of local knowledge only take place once these two factors shown by both the expert and novice which is the apprentice chosen by the expert of particular knowledge. The expert and apprentice will only exchange confidential information, after they have assessed the competence and reliability of the person who will receive the knowledge. The identified apprentice will be assessed by their technical capabilities, strategic and cultural compatibility. They will also negotiate the terms of the partnership depending on the participation, length, breadth and the way the knowledge is communicated. Due to this, local knowledge usually shared and passed on between trusted family members and rarely to the community. Instead it is passed on within family community such as from parents to their children, from grandparents to their grandchildren or from uncle or aunts to their niece or nephews. The expert in the family such as grandmother or the parents will identify and carefully select their apprentice to learn and practice the knowledge they have. However, not all knowledge will be shared and transferred to their apprentice due to their own reason to protect the knowledge.

According to World Health Organization, traditional healing has been defined as a diversity of practices, approaches, knowledge and beliefs incorporating plant, animal and mineral-based medicines. This includes, spiritual therapy, techniques, and exercises applied individually or combined to maintain health, treat illness or prevent it. Traditional healing has been widely used as prevention, diagnosis and treatment of an extensive ailment. It is an important alternative form of healthcare service to a person or community who is with or without geographic and financial access to modern medicine [5]. The Ministry of Health Malaysia defined traditional healing as traditional and complementary medicine other than practice of medicine or surgery by registered medical practitioners as defined by Medical Act 197. There are five traditional complementary medicine practiced in Malaysia which is Malay, Chinese and Indian traditional medicine, Homeopathy and Complementary Medicine, including traditional Malay massage [4].

In Malaysia, traditional healing among the Malay society was recorded since the $19^{\text {th }}$ century through Kitab Tib manuscript which uses natural resources, wafak (letters, numerals and diagrams), Quranic verse and doa (prayers and supplications) during the healing practice. At times, traditional Malay massage practitioner uses traditional healing as part of their practice whereby it uses a diversity of practices, approaches, knowledge and beliefs incorporating plants, animal, and mineral based medicine. This may include spiritual therapies, techniques and exercises, applied individually or in combination to maintain health in treating illness or to prevent it.

In the Malay society, healing practices utilizes natural resources mainly flora as remedies because it gives benefits for the body aligned with Islamic teachings. In an analysis on 'Kitab Tib' alone, the author recorded about 258 types of flora that can be found mostly locally. The use of herbs as the ingredients in these remedies proves that the Malay society already have its own traditional healing practices that was passed down from generation to generation even until today [6]. By participating, the knowledge on tacit knowledge can be transferred through learning and living practice between expert and novice. Learning is also seen as a way to gain respect from the community whereby skills are developed and incorporated through training and practice that can provide tangible benefits to the community [3].

The willingness and capacity of individuals or a community to share what they know and use what they learn plays an important role for local knowledge to be transferred. Therefore face-to-face interaction becomes the primary means in obtaining local knowledge from the source of knowledge [7]. Since that local knowledge are learnt from 'doing' and participation between the source and receiver of knowledge, local knowledge are more successful to be passed down if a face-to-face interaction takes place whereby the knowledge can be better exchanged and new knowledge that can improve the current practices of the identified local knowledge be developed. Expertise is developed through learning-by-doing, an apprentice are likely to practice under the guidance of a knowledgeable teacher for them to become an expert in the field. The more engaged a practitioner is with the activity, the better they become good at it 
[8]. Therefore, this paper attempts to explore on whether or not these traditional Malay massage practitioner would transfer their knowledge and how the knowledge is being passed down from expert to apprentice.

\section{Methodology}

This study involves selected traditional Malay massage practitioners in the northern of Malaysia on how they acquire their knowledge on traditional massage and how they manage the knowledge obtained. It also attempts to observe whether or not these traditional Malay massage practitioners would transfer their knowledge to their apprentice. Traditional massage practitioner is an expert in massaging people traditionally as their main activity. However, some practitioners may also offer massage treatment on women who recently gave birth. There were seven people involved in this study but for the purpose of this research, only four will be discussed.

\section{Results and Discussion}

According to Respondent A, a 34 year old traditional Malay massage practitioner, he learns how to massage people through observation from his grandfather who is also a massage practitioner. The knowledge usually would be passed down when an apprentice is in their 40s but because of his grandfather's health is deteriorating he had to learn from his grandfather as early as 18 years old. He doesn't know why out of all 80 grandchildren, he was chosen by his grandfather to learn about traditional massage. Upon returning to his village after being informed about his grandfather's health, he learns how to massage people from his grandfather after Maghrib prayer for a day. His grandfather use verses from the Quran in his healing practice as he believes that all diseases happen by the will of God. Method of healing depends on the type of disease of the patient. Other than that he also learns the type of food that needs to be avoided or eaten during healing process.

This means, out of all his grandchildren, Respondent A grandfather have already assessed who among them who is suitable to be passed down his knowledge on massage. Hence why, he was chosen as an apprentice and transferred his knowledge from his grandfather.

Through his grandfather, he not only learns how to heal but also learns to be a 'bidan' or midwife. Although he has the knowledge as a 'bidan', he doesn't deliver baby because he is a man and cannot touch women's private part. In spite of that, he learns how to make 'Minyak Celak' and 'Minyak Susuk' used by women. However, he usually buys the 'Minyak Urut' or oil for massage as the ingredients can only be obtained from the forest. As many people started to be convinced of his ability, his ability to heal people spread through word of mouth and receives patients from people in the south of Malaysia. Sometimes, he also receives non-muslim patients who come for massage after giving birth. During massage, he takes about one to two hours depending on the individual and the size of their veins. Every month, he treats more than 10 patients and receives payment in whatever his patients can afford. Although he doesn't set specific time to treat his patients, he does other work such as farming.

From this, we observe that his ability to massage people manage to gain the trust by the people who came for his treatment. People are more convinced as they hear from a other people they trust and seeks his treatment for massage as word of mouth is a powerful tool and easily believed as it is built on trust for a person to accept the information they get.

Respondent A also adds on that although he knows how to heal people such as 'Saka', hysteria, possessed, he do not know particular type of massage technique for broken bones because he is still young. His grandfather have set a criteria that only apprentice who reach the age 38 years old are qualified to learn how to treat broken bones. Therefore, he also continues the same method to people who wants to learn from him. He hopes to pass down his knowledge to his children when they reach the right age to learn which is between 30 to 40 years old. However, he is willing to teach other people within his family members depending on how much they can learn and compatibility of the apprentice in learning. For example, he tried to pass down the knowledge to his brother in law but after 44 days of learning one method, his body heat increased for a week and cannot withstand it. So they had to remove it and the transfer was not successful.

From the interview, we learn that Respondent A grandfather sets a certain criteria in order to select the most suitable apprentice and he tries to continue the method by passing down to his brother in law. According to his 
grandfather way, an apprentice should reach the age of 38 years old to be qualified to learn about massaging and treating broken bones. However, the knowledge could not be transferred as the brother in law couldn't stand the increasing body heat after a week of their apprenticeship. Although he is willing to teach other people within his family members, he still hopes that after his children reach the right age to transfer his knowledge, they will be able to learn and continue the knowledge passed down to them.

On contrary, for Respondent B, she learns from her great grandmother from her father side who is also a 'Bidan'. None of her siblings knows how to massage except her. She start giving service when she is 40 years old. Similarly with Respondent A, she doesn't know how to treat broken bones and only knows how to massage after giving birth and deliver baby. However, Respondent $\mathrm{C}$ makes her own massage oil from coconut and uses verses from the Quran in her healing practices. Normally, she starts massaging after 3 days when her patients gives birth and offers 'cukur jambul' service to shave a baby's hair. Her ability was spread through word of mouth and at times was invited to treat people in other cities such as Langkawi, Pulau Pinang, and Klang. Every massage also takes about one or two hour the most and she will advice on the type of food to avoid or eat during the healing process. However, some practices she no longer continued by new mothers as it is against the teachings of Islam. Some of her children have the ability to massage so other people will hire them as she is getting old. Although she practices traditional massage, Respondent B also uses modern complimentary medicine such as Gamat gel to heal wounds and goes to courses for midwife. However, she doesn't teach anyone her knowledge because no one wants to learn from her.

Meanwhile, for Respondent $\mathrm{C}$ the knowledge on massage was passed down quite mysteriously. She learns it through dreams and receives a black mark in her palate as a sign of 'wali' or a respectable person who have special power which she believes inherited in her family. Because of the black palate, her family is known as 'Tanah Hitam' or the black soil family. Similarly, she also use verses from the Quran in her healing practice. It is believed that whatever her family says will become true when it is said. Therefore, she uses her ability to make doa and prayer for the person who comes for treatment with very low fee. Strangely, she charges only RM1.20 for her service which is optional. Her reason was that she only wanted to help people with her ability

In Respondent D case, she inherited naturally from her family who is also a 'bidan' or midwife. She have the ability treat broken bones and sprained parts of the body. But for those who still cannot recover and asks for spiritual healing, she will politely decline. Since her mother was also a 'bidan', she also inherited the ability from her mother and the healing knowledge from her father's side who inherits a spiritual tiger passed down to their family to protect them from harm. Despite that, she uses Quranic verse in her treatment and certain type of Islamic prayers for treatment. However, she only treats women during massage and only massage up to the feet if she had to massage male patients. Her patients are required to bring a coconut which she will make oil from it where they will later use for massage. Sometimes, the patient brings their own oil massage which she later make doa and blow on the oil massage they brought. Usually she starts her service around 2 to $6 \mathrm{pm}$ and only gives service when asked to help. Some patients come all the way from Johor and Kuala Lumpur. According to Respondent D, none of her children have the ability and talent that she have now. Her youngest children who showed ability like her have passed away which she believes is because her child might grow up to become a bad person. She believes that those with her ability cannot talk about bad things and be mad at people. Although her grandchildren seem to show ability like her, she is not sure if she can passed down the knowledge as it is passed down through dreams like her.

\section{Conclusion}

To sum, knowledge transfer among traditional Malay massage practitioners can only take place when there is trust between the expert and apprentice. This knowledge is often passed down within their family members only. The skills and technique on traditional massage is learnt by the apprentice from experience and observation of the expert. However, some local knowledge cannot be passed down either because the apprentice is not ready in many forms (i.e. spiritual strength, compatibility, age maturity) to receive the knowledge or nobody is willing to learn from these experts and naturally gifted within particular family. Some practitioners don't necessarily stick to the same method and may generate their own knowledge in treating their patients by mixing with other types of massage practices. Although there is modern technique for massage available, rather than learnt by the community as a whole. The traditional massage remains only within the individual or limited number within the family community. 


\section{Acknowledgement}

The authors express their gratitude to the Malaysian Ministry of Higher Education for awarding the Long-Term Research Grant (LRGS, 203/PTS/6727002), Universiti Sains Malaysia and all involved in this study

\section{References}

1. Canagarajah, S. (2002) Reconstructing Local Knowledge, Journal of Language, Identity \& Education, 1:4, 243 259.

2. Rothernberg et. al, (2006) Tacit knowledge transfer and the knowledge disconnect, Journal of Knowledge Management, Vol. 10 pp. 6-18.

3. Furgal et. al (2011) "Transmission of environmental knowledge and land skills among Inuit Men in Ulukhaktok, Northwest Territories, Canada", Human Ecology Vol. 39, Issue 3, pp 271 - 288.

4. Pillay, M. S (2006) "Traditional \& Complementary Medicine in Malaysia", Ministry of Health Malaysia, International Conclave on Traditional Medicine, New Delhi, India. 16-17

5. (WHO, 2001).

6. Baharuddin \& Sidek (2010) Traditional healing in Malay culture: The Case of a Malay Manuscript of the $19^{\text {th }}$ century, International Conference of Sustainable Health Promotion.

7. Wang \& Wang (2012) Knowledge sharing, innovation and performance, Elsevier, Expert system with applications.

8. Abrams. L, Shields. M, Leonard. D et al. (2015), Using mentoring and storytelling to transfer knowledge in the workplace, Routledge, Journal of Management and Information Systems 